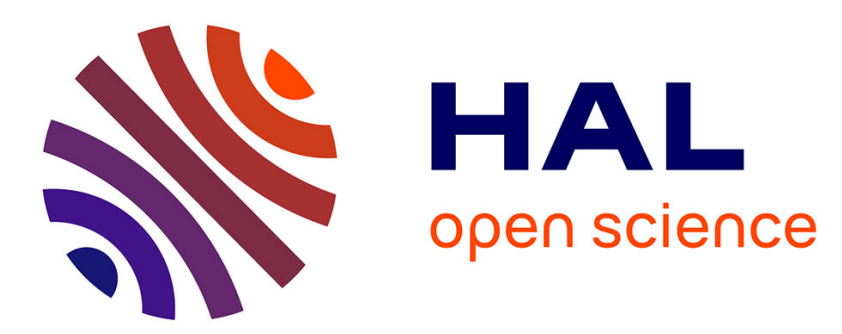

\title{
Comparative Statics of Joint Reproductive Allocation
} Jesús Alberto León, José Renato de Nóbrega Suárez

\section{To cite this version:}

Jesús Alberto León, José Renato de Nóbrega Suárez. Comparative Statics of Joint Reproductive Allocation. Journal of Theorical Biology, 2000, 205, pp.563 - 579. 10.1006/jtbi.2000.2086 . hal01558054

\section{HAL Id: hal-01558054 https://hal.science/hal-01558054}

Submitted on 7 Jul 2017

HAL is a multi-disciplinary open access archive for the deposit and dissemination of scientific research documents, whether they are published or not. The documents may come from teaching and research institutions in France or abroad, or from public or private research centers.
L'archive ouverte pluridisciplinaire HAL, est destinée au dépôt et à la diffusion de documents scientifiques de niveau recherche, publiés ou non, émanant des établissements d'enseignement et de recherche français ou étrangers, des laboratoires publics ou privés. 


\title{
Comparative Statics of Joint Reproductive Allocation
}

\author{
Jesús Alberto León*† and José Renato De Nóbrega $\$$
}

\begin{abstract}
†Sección de Ecología de Poblaciones, Laboratorio de Biología Teórica, Instituto de Zoología Tropical, Facultad de Ciencias, Universidad Central de Venezuela, Apartado 47058, Caracas 1041-A, Venezuela and $\ddagger$ Sección de Ecología de Comunidades y Sistemas, Laboratorio de Socioecología, Instituto de Zoología Tropical, Facultad de Ciencias, Universidad Central de Venezuela, Apartado 47058, Caracas 1041-A, Venezuela
\end{abstract}

(Received on 1 December 1999, Accepted in revised form on 28 April 2000)

\begin{abstract}
We perform a perturbation analysis (comparative statics) of how optimal reproductive effort and per offspring investment are jointly affected by different selective factors. The factors considered are: (1) mortality sources, classified according to affected stage ( juvenile or adult) and to its nature (avoidable or unavoidable), and (2) resource (energy) availability for the adult individual. The joint approach reveals both direct and indirect effects of each selective pressure. These interactive effects spring from the nonlinearity of reproductive expenditure, separated into a part devoted to endowing offspring (provisioning cost) and another part invested to make reproduction possible (requisite cost). The latter is envisioned as a reverse sigmoid function of fecundity (most models, so far, have considered only the first kind of cost). The indirect effects have the consequence of enlarging the class of selective pressures that can induce changes of offspring size and clutch size, as compared with current explanations. So, they illuminate new causes for some effects, and show new effects for some well-known selective causes. Several joint patterns in the two variables, shown by animals and plants in the field, can thus be given more appropriate interpretations than traditional, piecewise, ones.
\end{abstract}

(C) 2000 Academic Press

\section{Introduction}

The simultaneous differences in reproductive effort and offspring size observed in comparative studies of several organisms (recent reviews in Roff, 1992; Stearns, 1992; Charlesworth, 1994) cannot be accounted for in the current framework of separate models purporting to explain the various aspects of life-history evolution. To believe otherwise is perhaps to be deluded by the past overemphasis on $r / K$-selection, "bet hedging" or other "blanket" theories (Charlesworth, 1994 , p. 226) which were misinterpreted as general explanations of suites of life history traits.

\footnotetext{
*Author to whom correspondence should be addressed.
}

We offer here what we consider to be the best way to tackle such problems: to build up explicit integrated models so as to properly explore its consequences. We concentrate on reproductive effort and investment per offspring, but the same approach should be extended to include other features. In fact, an important related attempt to put together life-historic and sexual parameters has been recently undertaken by Zhang and his associates (Zhang \& Wang, 1994; Zhang et al., 1996; Zhang \& Jiang, 1997, 1998; Zhang, 1998) although they have mainly intended to delimit the validity conditions of traditional separate models.

There is an obvious relation between total reproductive effort and per offspring investment, 
and thus a possibility of trade-offs between lifehistory traits determined by these energetic variables. Total effort is the proportion of available resources dedicated to reproduction whereas per offspring investment is the quantity of resources put into each offspring (offspring energetic size). Their interplay determines the number and size of descendants. For a given total reproductive effort, an increase in per offspring effort occurs at the expense of a reduction in fecundity: the number-size trade-off. A second trade-off, between adult survival and fecundity, is possible: the so-called cost of reproduction (Calow, 1979; Bell, 1980; Reznick, 1985, 1992; Partridge, 1989; Mole, 1994; Sinervo \& De Nardo, 1996). But the need for a simultaneous treatment of both energetic variables has rarely been recognized, although stressed by León (1984) and Winkler \& Wallin (1987). The current theory has considered energetic variables in a separate fashion, notwithstanding their interactive character. Classical reproductive effort models analyse ultimate factors determining optimal total effort, including the survival cost of reproduction, but ignores its subdivision among offspring (Gadgil \& Bossert, 1970; Schaffer, 1974; Charlesworth \& León, 1976; León, 1976). On the other hand, models devoted to optimal per offspring reproductive investment are either formulated on the implicit or explicit assumption of constant total reproductive effort (e.g. Smith \& Fretwel, 1974) or take such effort as an evolutionary variable that does not influence adult survival, omitting the cost of reproduction (e.g. Parker \& Begon, 1986).

The model of simple perennial life histories that we present here puts together these two trade-offs, essentially by including in the energy budget a nonlinear term referred to as requisite cost. This is the energy required to make possible offspring production, invested in structures or activities, and different from the allotment dedicated to provisioning the offspring. We show that the nonlinearity of this term leads necessarily to link the optimizations involved, thus differing from the outcomes of the two other integrated models existing so far: that of Winkler \& Wallin (1987), who totally ignored this complementary cost, and that of Zhang (1998), who considered it linear. The coupling of optimizations turns out to be necessary to understand the field results of joint comparisons, mentioned already, which we detail in the discussion. We analyse our model within an optimization framework by a comparative statics approach.

In mathematical economics, comparative statics investigates how a function optimum is affected by perturbations in characteristic parameters. In evolutionary ecology, strategic analysis finds out constrained phenotypes which optimize (maximize) fitness, for some given environment (Maynard Smith, 1978; Parker \& Maynard Smith, 1990; Charlesworth, 1994). Here, comparative statics would ask for the motion of optimal phenotypes when the environmental parameters are perturbed. Thus, comparative statics could render two services to evolutionary ecology. First, it allows a kind of sensitivity analysis with respect to environmental parameters, which could discern the strength, direction and interconnection of the selective pressures acting in some situation. Second, it may provide the theoretical underpinning for a comparative analysis of adaptive effects resulting from related environments.

In life-history theory, such a kind of perturbation analysis has appeared only sporadically (Goodman, 1979; Law, 1979; Michod, 1979; Brown \& Venable, 1986; Sargeant et al., 1987; León, 1988; Pásztor, 1988; Nossbaun \& Schultz, 1989; Meszèna and Pásztor, 1990). But Caswell \& Real (1987), recognizing its full range of potential applications, recommended its wider use, inspired by the benefits reaped from the approach by mathematical economics. But, in their attempt to analyse life histories, they merely translated directly some parts of consumer microeconomics (Henderson \& Quandt, 1971). León (in press) has exposed some inconsistencies resulting from such a procedure and, endorsing their proposal of using comparative statics, offered some alternatives. Hernández \& León (1995), in turn, have extended the approach to age-structured and density-dependent life histories and also to sizestructured ones (Hernández \& León, 2000). Kisdi \& Meszèna (1993) used it to study the joint effect of stochastic fluctuations and density dependence, whereas Kisdi et al. (1998) considered the shaping of reaction norms by individual optimization. Now, comparative statics requires a clear stipulation of the environmental parameters 
affecting the components of fitness, because the perturbation of these parameters is central to the approach. An obvious first approximation consists of discriminating among mortality factors which affect different stages of the life history. León $(1983,1988)$ has suggested an additional conceptualization: the contrast between unavoidable and avoidable mortality. A given mortality source is unavoidable if its effect is independent of any organism's defense effort. If its impact can be counteracted through energy investment on survival, mortality is avoidable. León has studied the effect of both types of mortality solely on total reproductive effort. Another parameter deserving attention is environmental richness as represented by the total energy available per capita. We explore the influence of all these parameters on optimal values of the energetic variables characterizing the life history and thereby tackle some classical questions on optimal clutch size and offspring size.

León $(1983,1988)$ posed the distinction between "direct" and "compensatory" strategies, recently explored again by Hernández \& León (1995). We surmise one additional concept, that of indirect compensatory strategies (see the discussion in the section modifying unavoidable mortality), to account for some responses appearing in systems with interactive effects, as the one studied herein.

\section{The Model}

The model assumes an asexual organism with a biphasic life history: a non-reproductive (offspring), and a reproductive (adult) stage. Reproduction occurs in discrete episodes. In each episode, the adult fecundity is $B$, and its chance of surviving to the next reproductive episode is $P$. The newborn has a probability $S$ of reaching maturity. The period between reproductive episodes coincides exactly with the time elapsed from birth to maturation. The change in numbers of adults $(N)$ is given by $N_{(t+1)}=\lambda N_{(t)}$ (Charnov \& Shaffer, 1973), where

$$
\lambda=B S+P
$$

The adult clone population growth rate $(\lambda)$ is a measure of fitness, a combination of life history traits. Assuming a density-independent and constant environment, the life history favored by natural selection is the one endowed with maximal $\lambda$.

To pose asexual models has been a favorite gambit of strategic analysis in evolutionary ecology. This usually allows a clear-cut examination of the consequences of natural selection acting in specified environmental regimes and constrained by certain assumed trade-offs (Parker \& Maynard Smith, 1990; Seger \& Stubblefeld, 1996). Hence, the "as if asexual" approach, adopted for heuristic reasons, became common practice for modeling density-independent and density-dependent selection (Charlesworth, 1994) and even frequency-dependent selection in the context of evolutionary game theory (Maynard Smith, 1982). The extension to sexual populations is not always straightforward, but often works properly, with the rate of growth of the heterozygote "population", as compared with that prevailing in the "established" population, deciding whether a gene can invade or not (Charlesworth, 1994). Another method is to interpret the population per capita rate of increase as the objective function to be optimized, justifying it by quantitative genetics arguments referring to the change of the mean of one or several characters (Charlesworth, 1990, 1994; Stearns, 1992; Roff, 1992,1994). In this spirit, we pose our models as if asexual, but then occasionally reason in terms of costs characteristic of sexual organisms, and examine sexual examples to validate our conclusions.

Having formulated the basic demographic model, we define the following energetic variables: $E$ is the total energy gathered by an adult individual during the period between reproductive episodes. $\varepsilon$ the total reproductive effort, the fraction of $E$ put into reproductive activities $(0 \leqslant \varepsilon \leqslant 1)$. The remaining fraction is devoted to adult survival and is denominated "survival effort" $(\sigma)$. Thus, $\varepsilon+\sigma=1$. $e$ is per offspring reproductive investment, the amount of energy put into each offspring, or energetic size $(0 \leqslant e \leqslant E \varepsilon)$.

For a given level of energy per adult $(E)$, the fecundity $B$ is determined by total reproductive effort $(\varepsilon)$ and per offspring investment $(e)$. If we take $B$ as an increasing function of $\varepsilon$ and a general 
decreasing function of $e$, then

$$
B=B(\varepsilon, e ; E),
$$

where

$$
\left(\frac{\partial B}{\partial \varepsilon}\right)>0 \text { and }\left(\frac{\partial B}{\partial e}\right)<0
$$

The environmental parameter $E$ determines the scale of possible values of $B$. In the present study, $B$ will be determined as an implicit function of $\varepsilon$ and $e$ through the imposition of a budget constraint which will be discussed in the forthcoming section.

The adult and offspring survival probabilities $(P$ and $S)$ are partitioned into survival to avoidable and unavoidable mortality factors. Thus, $\pi\left(\mu_{a}\right)$ is the adult probability of surviving to an unavoidable mortality agent of intensity $\mu_{a} . \phi\left(\mu_{o}\right)$ is the offspring survival probability to an unavoidable mortality source of intensity $\mu_{o}$. $p\left(\varepsilon ; m_{a}, E\right)$ is the adult probability of surviving to an avoidable mortality factor of intensity $m_{a}$. This probability depends on the survival effort $\sigma$ and thus on $\varepsilon$, the total reproductive effort. The probability $p$ decreases as $m_{a}$ increases and it is a strictly decreasing concave downward function of $\varepsilon$. Total energy per adult $(E)$ determines the scale of potential values of $p$. Thus,

$$
\frac{\partial p}{\partial m_{a}}<0, \quad \frac{\partial p}{\partial \varepsilon}<0 \quad \text { and } \quad \frac{\partial^{2} p}{\partial \varepsilon \partial m_{a}}<0
$$

or equivalently

$$
\frac{\partial^{2} p}{\partial \sigma \partial m_{a}}>0
$$

the negative sign of the first mixed derivative indicates that we assume the mortality source to be easy to avoid (EAM), as León (1988) has deemed this case. It means that the decline of $p$ due to the increase of $m_{a}$ is less pronounced at low levels of $\varepsilon$, i.e. high levels of survival effort $\sigma$ : defense is possible and effective [Fig. 1(a)]. On the contrary, a positive mixed derivative would mean that the slope $\partial p / \partial m_{a}$ becomes more pronounced as $\varepsilon$ decreases, i.e. as the survival effort $\sigma$ increases: defense is not effective and mortality
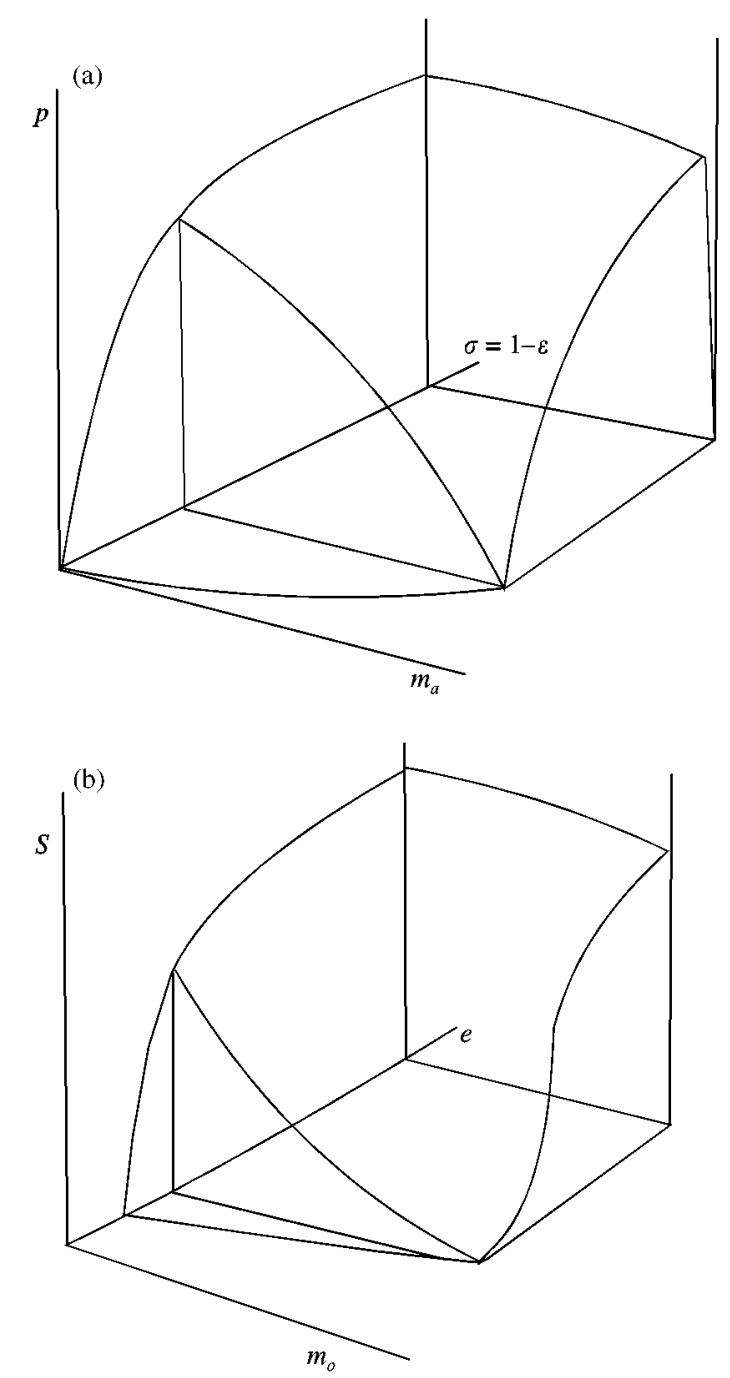

FIG. 1. Adult and offspring survival functions. (a) The adult probability of surviving $(p)$ is represented as a function of the intensity of mortality factors $\left(m_{a}\right)$ and the reproductive effort $(\varepsilon)$; the slope $\partial p / \partial m_{a}$ is less pronounced at low levels of $\varepsilon$ (high levels of survival effort, $\sigma$ ): mortality is easy to avoid (EAM). (b) The offspring probability of surviving $(s)$ is shown as a function of the intensity of mortality sources $m_{o}$ and energetic size $(e)$; the slope $\partial s / \partial m_{o}$ is less pronounced in high levels of $e$ : mortality is easy to avoid (EAM).

is hard to avoid (HAM). We focus our attention on the EAM case because HAM is qualitatively similar to unavoidable mortality.

$s\left(e ; m_{o}\right)$ is the offspring probability of surviving to avoidable mortality sources of intensity $m_{o}$, depending on its energetic size $(e), s$ increases with $e$ and decreases with $m_{o}$. Thus,

$$
\frac{\partial s}{\partial m_{o}}<0, \quad \frac{\partial s}{\partial e}>0 \quad \text { and } \quad \frac{\partial^{2} s}{\partial e \partial m_{o}}>0,
$$


where the sign of the mixed derivative expresses the easily avoidable condition of the mortality source [Fig. 1(b)]. Notice that this $m_{o}$ refers to those hazards to the offspring that can be combated by the energetic investment of the adult, i.e. by some kind of protection conferred by this. Once the offspring becomes an independent juvenile there is nothing the adult can do about its protection and so we include this remaining survivorship within the survival to unavoidable factors. There is, of course, an additional strategic problem that we avoid considering here: how does the juvenile allocate its independently procured energy between growth and survival?

According to these assumptions, the adult and offspring survival probabilities are reexpressed by

$$
\begin{gathered}
P\left(\varepsilon ; \mu_{a}, m_{a}, E\right)=\pi\left(\mu_{a}\right) p\left(\varepsilon ; m_{a}, E\right), \\
S\left(e ; \mu_{o}, m_{o}\right)=\phi\left(\mu_{o}\right) s\left(e ; m_{o}\right) .
\end{gathered}
$$

The fitness index $\lambda$ is a function of the evolutionary energetic variables $(\varepsilon, e)$ and the environmental parameters $(m, \mu$ and $E)$. Denoting by $\mathbf{w}$ the column vector of reproductive allotments and by $\mathbf{q}$ the column vector of parameters:

$$
\lambda=\lambda(\mathbf{w} ; \mathbf{q})
$$

where

$$
\begin{gathered}
\mathbf{w}^{\mathbf{T}}=\left(w_{1}, w_{2}\right)=(\varepsilon, \mathrm{e}) \quad \text { and } \\
\mathbf{q}^{\mathbf{T}}=\left(q_{1}, q_{2}, q_{3}, q_{4}, q_{5}\right)=\left(\mu_{o}, \mu_{a}, m_{o}, m_{a}, E\right) .
\end{gathered}
$$

Optimal levels of reproductive allocations are obtained by setting the partial derivatives of $\lambda$ with respect to the energetic variables equal to zero (Chiang, 1974):

$$
\frac{\partial \lambda(\mathbf{w} ; \mathbf{q})}{\partial \mathbf{w}}=\mathbf{0}
$$

The second-order condition required to guarantee a maximum of $\lambda$ is $\mathrm{d}^{2} \lambda=\mathrm{d} \mathbf{w}^{\mathbf{T}} \cdot \mathbf{H} \cdot \mathrm{d} \mathbf{w}<0$, where $\mathbf{H}$ is the Hessian matrix of second partial derivatives of $\lambda$ with respect to the energetic variables. The second-order condition in turn requires

$$
h_{11}=\frac{\partial^{2} \lambda}{\partial \varepsilon^{2}}<0, \quad h_{22}=\frac{\partial^{2} \lambda}{\partial e^{2}}<0
$$

and

$$
D=\left(\frac{\partial^{2} \lambda}{\partial \varepsilon^{2}}\right)\left(\frac{\partial^{2} \lambda}{\partial e^{2}}\right)-\left(\frac{\partial^{2} \lambda}{\partial \varepsilon \partial e}\right)^{2}>0
$$

The two first-order conditions characterizing the maximum are

(a)

$$
\begin{aligned}
\frac{\partial \lambda}{\partial \varepsilon}= & \frac{\partial B(\varepsilon, e ; E)}{\partial \varepsilon} s\left(e ; m_{o}\right) \phi\left(\mu_{o}\right) \\
& +\frac{\partial p\left(\varepsilon ; m_{a}, E\right)}{\partial \varepsilon} \pi\left(\mu_{a}\right)=0 .
\end{aligned}
$$

This means that at the optimum, the marginal increase in effective fecundity resulting from investing effort in producing more offspring equals the marginal increase in adult survival that would result from decreasing such an effort. The marginal gains from investing in fecundity and survival become equal.

(b)

$$
\begin{aligned}
\frac{\partial \lambda}{\partial e}= & \frac{\partial B(\varepsilon, e ; E)}{\partial e} s\left(e, m_{o}\right) \phi\left(\mu_{o}\right) \\
& +B(\varepsilon, e ; E) \frac{\partial s\left(e, m_{o}\right)}{\partial e} \phi\left(\mu_{o}\right)=0
\end{aligned}
$$

This implies that, at the optimum, the marginal increase in effective fecundity gained by investing energy in offspring survival equals the increase that would result from augmenting numbers by diminishing offspring size.

\section{Independent or Joint Optimization?}

The traditional models have been posed as if it were possible to obtain independently the optimal values of $\varepsilon$ and $e$. Thus, the reproductive effort models (Gadgil \& Bossert, 1970; Schaffer, 1974; Schaffer \& Gadgil, 1975; Charlesworth 
\& León, 1976; León, 1976; Law, 1979; Michod, 1978; Charlesworth, 1994) ignored egg size, and vice versa (Vance, 1973a,b; Smith \& Fretwell, 1974; Brockelman, 1975; Parker \& Begon, 1986; Lloyd, 1987; Sargeant et al., 1987; Venable, 1988; Morris, 1996; Geritz, 1995). Hence, not only pedagogical reasons but perhaps also tradition led to separate treatments of both optimizations in two recent comprehensive books on life histories (Roff, 1992; Stearns, 1992). But eqns (8) and (9) define, in general, each optimum as a function of the other evolutionary variables, $\hat{\varepsilon}(e)$ and $\hat{e}(\varepsilon)$. Thus, we have two curves in the $e-\varepsilon$ plane, corresponding to ridges of $\lambda$, and the joint optimum (if only one exists) occurs where these curves cross each other. We can easily get by implicit differentiation of eqns (8) and (9), the derivative of curves $\hat{\varepsilon}(e)$ and $\hat{e}(\varepsilon)$ :

$$
\begin{aligned}
& \frac{\mathrm{d} \hat{\varepsilon}}{\mathrm{d} e}=-\frac{\left(\partial^{2} \lambda / \partial \varepsilon \partial e\right)}{\left(\partial^{2} \lambda / \partial \varepsilon^{2}\right)} \quad \text { and } \\
& \frac{\mathrm{d} \hat{e}}{\mathrm{~d} \varepsilon}=-\frac{\left(\partial^{2} \lambda / \partial \varepsilon \partial e\right)}{\left(\partial^{2} \lambda / \partial e^{2}\right)}
\end{aligned}
$$

Since both denominators are assumed to be negative, the sign of these derivatives is determined by the numerator, i.e. the mixed second partial derivative evaluated along $\hat{\varepsilon}(e)$ [eqn (8)] and $\hat{e}(\varepsilon)$ [eqn (9)], respectively.

Only in very special cases can the optimizations (or at least one of them) be independent. This happens in the few antecedents we know of joint allocation models (Winkler \& Wallin, 1987; Zhang, 1998; Zhang \& Jiang, 1998), and is due to the special form of their assumptions. Winkler and Wallin use a form of $B$ (the same form used so far in all egg size models, $B=E \varepsilon / e$ ) which necessarily leads to an independent determination of $e$, although not of $\varepsilon$, which is a function $\hat{\varepsilon}(e)$ as we shall see presently. Also, Parker \& Begon (1986), in a model which considers together foraging time and egg size in insects, obtained initially uncoupled optimizations of these variables, coupled thereafter by introducing sibling competition.

Suppose, as Winkler \& Wallin (1987) do, that $B=E \varepsilon / e$, which is the fecundity function assumed in all the per offspring investment models published so far. Then eqn (9) becomes

$$
\frac{\partial \lambda}{\partial e}=B\left\{-\frac{S}{e}+\frac{\partial S}{\partial e}\right\}=0
$$

which is the optimization condition first deduced by Smith \& Fretwell (1974). The mixed partial is in this case,

$$
\frac{\partial^{2} \lambda}{\partial \varepsilon \partial e}=\frac{\partial B}{\partial \varepsilon}\left\{-\frac{S}{e}+\frac{\partial S}{\partial e}\right\},
$$

which is equal to zero if evaluated along the curve $\hat{e}(\varepsilon)$, given by eqn (11). Therefore, the derivative of the curve is zero, and the curve is a vertical straight line erected at some constant value $\hat{e}$ determined by eqn (11). But the mixed partial is not zero when evaluated along $\hat{\varepsilon}(e)$. As $e$ increases, the slope $\mathrm{d} S / \mathrm{d} e$ is at first steeper than $S / e$, then equal (at $\hat{e}$ ) and then less steep. The derivative $\mathrm{d} \hat{\varepsilon} / \mathrm{d} e$ is therefore initially positive, then zero, then negative (Fig. 2). In summary, when $B=E \varepsilon / e, \hat{e}$ can be obtained independently, and then $\hat{\varepsilon}$ is merely $\varepsilon(\hat{e})$.

Now, not all the energy devoted to reproduction is divided among the eggs or seeds. Zhang (1998) and Zhang \& Jiang (1998) assumed that in plants the provisioning of seeds happens after their number has been determined. Thus, female allocation includes two terms: one that determines numbers, taken as merely proportional to these (say $k \cdot B$ ), and another allotted among

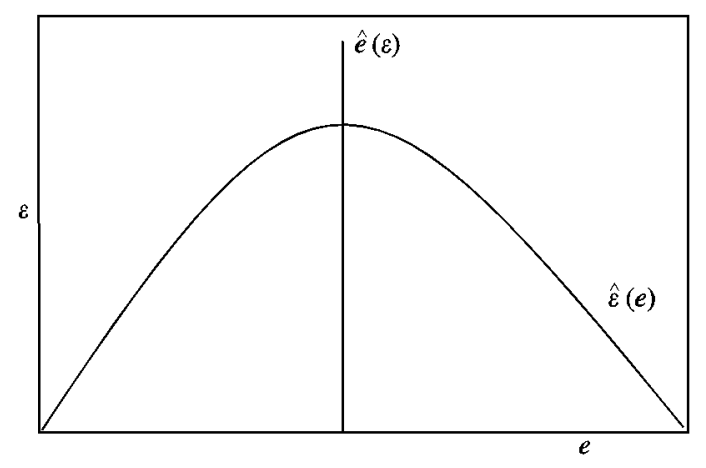

FIG. 2. The curves $\hat{\varepsilon}(e)$ and $\hat{e}(\varepsilon)$ in the plane $\varepsilon-e$ when the fecundity function assumed is $B=E \varepsilon / e$. The optimum occurs where the curves cross each other (block dot). Curve $\hat{e}(\varepsilon)$ is a vertical straight line while curve $\varepsilon(\hat{e})$ reaches a maximum when it crosses $\hat{e}(\varepsilon)$. In this case, $\hat{e}$ can be obtained independently while $\hat{\varepsilon}$ is merely $\varepsilon(\hat{e})$. 
offspring to determine their size, which would be the traditional $B e$. But this recognition of another component in the allocation constraint, insofar as it is linear, keeps the optimizations independent, as Zhang (1998) remarked.

However, such a linearity ignores the nature of some requisite processes involved in the determination of numbers. For instance, Zhang (1998) and Zhang \& Jiang (1998) assume, invoking respectable antecedents (Charnov, 1982; Charlesworth, 1994), that pollen availability does not limit female fecundity. But Sakai \& Sakai (1995) (see also Sakai, 1995) emphasized flower construction as required for attracting pollinators, an investment assumed to exhibit diminishing returns. In their model, such a component is crucial to explain the positive relationship between plant size and seed size, found by them in Lilium auratum and further documented by Sakai (1996) in several outcrossing plants.

The whole field of sexual selection (Harvey \& Bradbury, 1991; Ryan, 1997) illustrates expenditure fuelled to reproduction but not put into each offspring. It is blatantly deployed in males but involves females as well. To give an example, the success of external fertilization demands aggregation and synchronous spawning (Babcock et al., 1992) and often to endow eggs with chemical attractants or accessory structures (Miller, 1985; Bucland-Nicks, 1993; Podolsky \& Strathman, 1996). Thus, Low (1978) separated reproductive effort into mating effort and caring effort, to understand reproductive strategies in marsupials, and Sargeant (manuscript) has used this distinction to model sexual investment in male sticklebacks. But sexual structures or behaviors are not the only requirements previous and/or concomitant to progeny production. There are others, even in asexual organisms (Sibly \& Calow, 1982) which draw their resources from reproductive effort. Reekie \& Bazzaz (1987) point out that, in plants, reproduction involves not only the production of flowers and fruits, but also of various ancillary or support structures. Calow (1979) has discussed physiological and behavioral costs of reproduction in animals (see also Sibly $\&$ Calow, 1986). Some of these are not involved in the direct endowment that determines progeny size.

We shall include, therefore, a nonlinear term $C(B)$ in the reproductive budget, besides the traditional $B e$ term:

$$
E \varepsilon=B e+C(B)
$$

We shall call as "requisite cost" this nonlinear function, and "provisioning cost" the term Be. Thus, we define the relationship between fecundity $B$, reproductive effort $\varepsilon$, and progeny size $e$, through a cost constraint, in the manner of production theory in microeconomics (Henderson \& Quandt, 1971; Silberberg, 1978).

We postulate this $C(B)$ function to be increasing and reverse sigmoid (downward concaveconvex). That is, the first derivative is always positive $(\mathrm{d} C / \mathrm{d} B>0)$, and the second derivative changes from negative to positive: $\mathrm{d}^{2} C / \mathrm{d} B^{2}<$ $0 \rightarrow \mathrm{d}^{2} C / \mathrm{d} B^{2}>0$. Figure 3 presents two examples. In Fig. 3(a) there is a large branch exhibiting diminishing difficulties for offspring production (second derivative negative) and a short branch with increasing difficulties. The other example [Fig. 3(a)] shows opposite characteristics. These two examples, of course, are in the way to the extremes of pure concavity $\left(\mathrm{d}^{2} C / \mathrm{d} B^{2}<0\right)$ and pure convexity $\left(\mathrm{d}^{2} C / \mathrm{d} B^{2}>0\right)$.

Our reasons for using this form for the requisite cost are the same as those prevailing in economic theory: the first units produced usually require special efforts which can then be partially capitalized on for adding more easily further units. Eventually, increasing marginal difficulties supervene (see Henderson \& Quandt, 1971, Fig. 3.6). These, of course, are the reasons that led Taylor et al. (1974), León (1976), and Schaffer \& Rosenzweig (1977) to consider sigmoid (convex-concave) curves for their curves of effective fecundity (our $B S$ ) vs. reproductive effort. Also, Sakai (1996) postulated a sigmoid pollinization function of the allocation to flower attractiveness. It is interesting that Sikes (1998) measured lactation costs as a function of litter size in the grasshopper mouse Onychomys leucogaster and found a reverse sigmoid (concave-convex) curve of the kind which we postulate for our $C(B)$. He has recently delved into the implications of such a curve in litter size problems (Sikes, 1998).

The consequences of including our "requisite cost" function in the reproductive budget will be presently explored. Equation (13) leads to the 

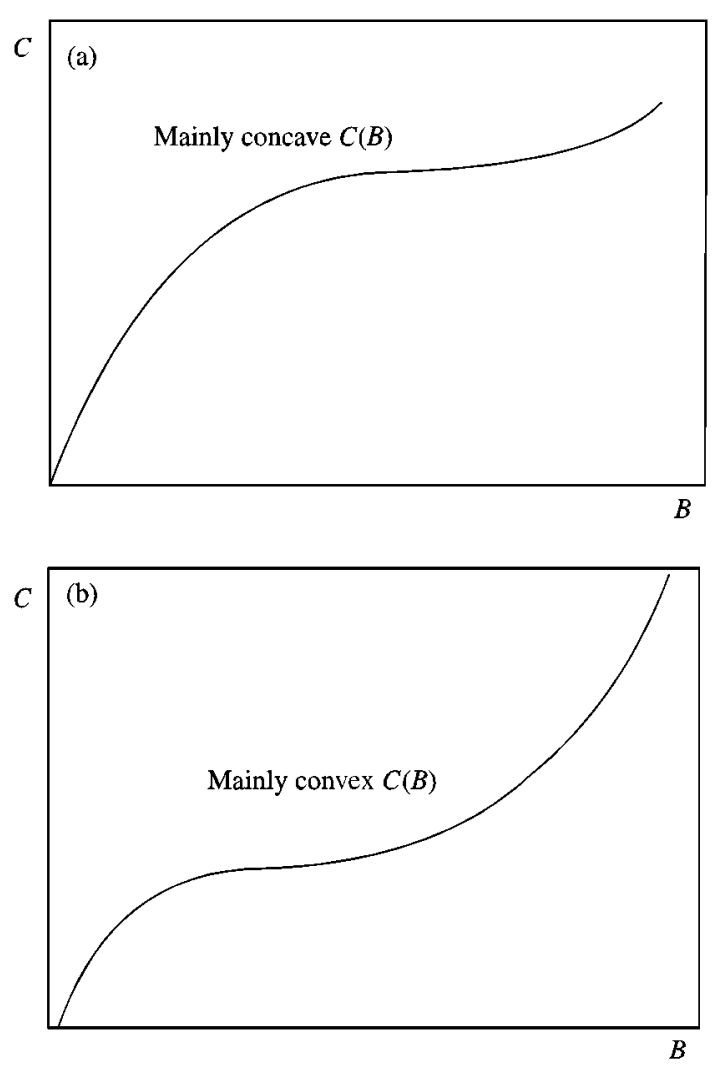

FIG. 3. Two examples of increasing and reverse sigmoid $C(B)$ functions (downward concave-convex). In these functions the first derivative is always positive $(\mathrm{d} C / \mathrm{d} B>0)$ while the second derivative changes from negative to positive: $\mathrm{d}^{2} C / \mathrm{d} B^{2}<0 \rightarrow \mathrm{d}^{2} C / \mathrm{d} B^{2}>0$. (a) The $C(B)$ function is mainly concave: it shows a large branch exhibiting diminishing difficulties for offspring production (second derivative is negative) and a short branch with increasing difficulties (second derivative is positive). (b) The $C(B)$ function is mainly convex: the initial branch with diminishing return is short while the second branch with increasing return is large.

derivatives:

$$
\begin{gathered}
\frac{\partial B}{\partial \varepsilon}=\frac{E}{e+(\partial C / \partial B)}, \\
\frac{\partial B}{\partial e}=-\frac{B}{e+(\partial C / \partial B)} .
\end{gathered}
$$

Notice that eqn $(15 \mathrm{~b})$ gives an interesting form to eqn (9), the condition for optimal propagule size:

$$
\frac{\partial \lambda}{\partial e}=B\left\{-\frac{S}{e+(\partial C / \partial B)}+\frac{\partial S}{\partial e}\right\}=0
$$

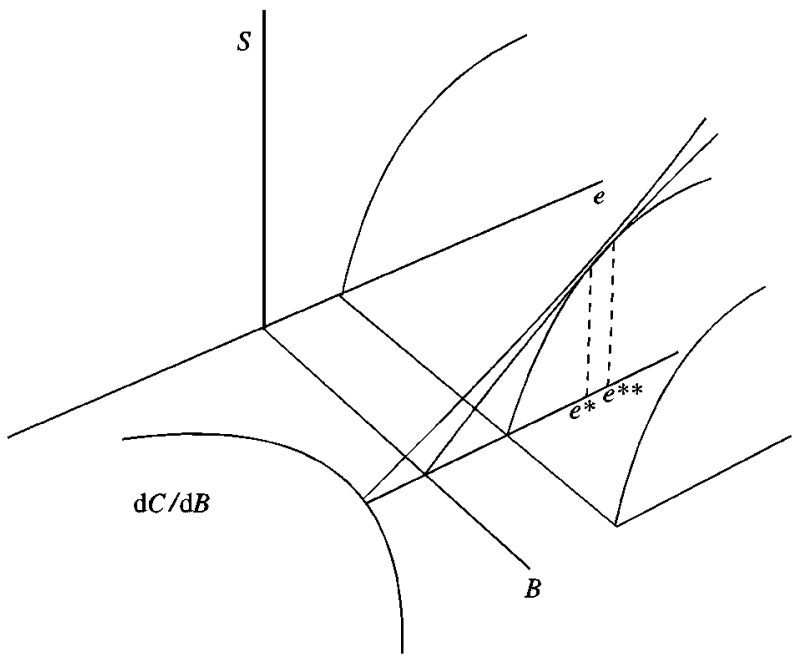

FIG. 4. Consequences of including a "requisite function" $C(B)$ in the reproductive budget: effects on the optimal propagule size. The graph shows the offspring survival (s) as a function of offspring size $(e)$ and offspring number $(B)$ (right-side), and the curve representing the derivative $\mathrm{d} C / \mathrm{d} B$ (bottom left-side). The condition for optimal propagule size requires that: $\partial S / \partial e=S / e+(\partial C / \partial B)$. Instead of the classical Smith-Fretwell condition-equality of the derivative $\mathrm{d} S / \mathrm{d} e$ with the quotient $S / e$ - we have an additional term $\mathrm{d} C / \mathrm{d} B$ in the denominator of the quotient, which bids for an optimal propagule size $\left(e^{* *}\right)$ larger that the Smith-Fretwell size $\left(e^{*}\right)$. If $C(B)$ is not linear, the term $\mathrm{d} C / \mathrm{d} B$ is a function of $e$ and $\varepsilon$, and its optimal value cannot be independently determined: the optimizations of both efforts must be linked. If $C(B)$ is linear then $\mathrm{d} C / \mathrm{d} B$ is a constant and the optimization of $e$ is independent of $\varepsilon$.

Comparing with eqn (11), we see that instead of the classical Smith-Fretwell condition (equality of the derivative $\mathrm{d} S / \mathrm{d} e$ with the quotient $S / e$ ) we have an additional term $\mathrm{d} C / \mathrm{d} B$ in the denominator of the quotient, which bids for an optimal propagule size larger than the Smith-Fretwell size. Moreover, this term is a function of $e$ and the other variable, $\varepsilon$, so that the optimal value of $\mathrm{d} C / \mathrm{d} B$ cannot be independently determined, and the two optimizations must be linked. Figure 4 shows a graphical interpretation of this condition. Of course, if $C(B)$ is linear, as posited by Zhang (1998), $\mathrm{d} C / \mathrm{d} B$ is a constant [see Fig. 3(a) of Zhang, 1998].

Developing the crucial mixed partial in the numerator of eqns (10), which determine the sign of the derivatives of the two curves $\hat{\varepsilon}(e)$ and $\hat{e}(\varepsilon)$, we obtain

$$
\frac{\partial^{2} \lambda}{\partial \varepsilon \partial e}=\frac{\partial^{2} B}{\partial \varepsilon \partial e} S+\frac{\partial B}{\partial \varepsilon} \frac{\partial S}{\partial e},
$$


which can be rewritten, after some rearrangement, as

$$
\frac{\partial^{2} \lambda}{\partial \varepsilon \partial e}=\frac{1}{B} \frac{\partial B}{\partial \varepsilon}\left\{\frac{\partial \lambda}{\partial e}+S\left(\frac{\partial B}{\partial e}\right)^{2} \frac{\partial^{2} C}{\partial B^{2}}\right\} .
$$

By definition, $(\partial \lambda / \partial e)=0$ along $\hat{e}(\varepsilon)$ and the derivative of the curve $\hat{e}(\varepsilon)$ will be governed by $\left(\partial^{2} C / \partial B^{2}\right)$. So, if $C(B)$ were linear, with $\left(\partial^{2} C / \partial B^{2}\right)$ $=0$, as assumed by Zhang (1998), we would have the same results obtained before [when $C(B)$ $=0)$ ] for the model of Winckler \& Wallin (1987), and the separation of optimizations holds. Figure 2 continues to represent this case.

However, when $C(B)$ adopts the forms represented in Fig. 3, the optimizations are necessarily linked. When $C(B)$ has a long branch with positive $\left(\partial^{2} C / \partial B^{2}\right)$, as in Fig. 3(a), the curve $\hat{\varepsilon}(e)$ grows for a long while before reaching its maximum at $e=\hat{e}$, whereas $\hat{e}(\varepsilon)$ has the form determined by $\partial^{2} C / \partial B^{2}$ alone. The two curves cross when the derivatives of both $\hat{\varepsilon}(e)$ and $\hat{e}(\varepsilon)$ are positive. This is represented in Fig. 5(a). Otherwise, if the branch with negative $\partial^{2} C / \partial B^{2}$ prevails, as in Fig. 3(b), the curve $\hat{\varepsilon}(e)$ reaches its maximum soon, and the two curves cross when their derivatives are negative, as shown in Fig. 5(b).

\section{Comparative Statics (Perturbation Analysis)}

Differentiating implicitly eqn (7) with respect to $\mathbf{q}$ we obtain the effect on $\hat{w}$ produced by infinitesimal changes of the existing level of environmental parameters:

$$
\frac{\mathrm{d} \hat{w}}{\mathrm{~d} q}=-\left(\frac{\partial^{2} \lambda(w ; q)}{\partial w^{2}}\right)^{-1}\left(\frac{\partial^{2} \lambda(w ; q)}{\partial w \partial q}\right) .
$$

In detail, the effect of an infinitesimal change of parameter $q_{i}$ on and $\hat{e}$ is given by

$$
\frac{\mathrm{d} \hat{\varepsilon}}{\mathrm{d} q_{i}}=-\frac{\partial^{2} \lambda / \partial \varepsilon \partial q_{i}+\partial^{2} \lambda / \partial \varepsilon \partial e\left(\mathrm{~d} \hat{e} / \mathrm{d} q_{i}\right) \hat{\varepsilon}}{\Delta_{1}}
$$

and

$$
\frac{\mathrm{d} \hat{e}}{\mathrm{~d} q_{i}}=-\frac{\partial^{2} \lambda / \partial e \partial q_{i}+\partial^{2} \lambda / \partial \varepsilon \partial e\left(\mathrm{~d} \hat{\varepsilon} / \mathrm{d} q_{i}\right) \hat{e}}{\Delta_{2}},
$$
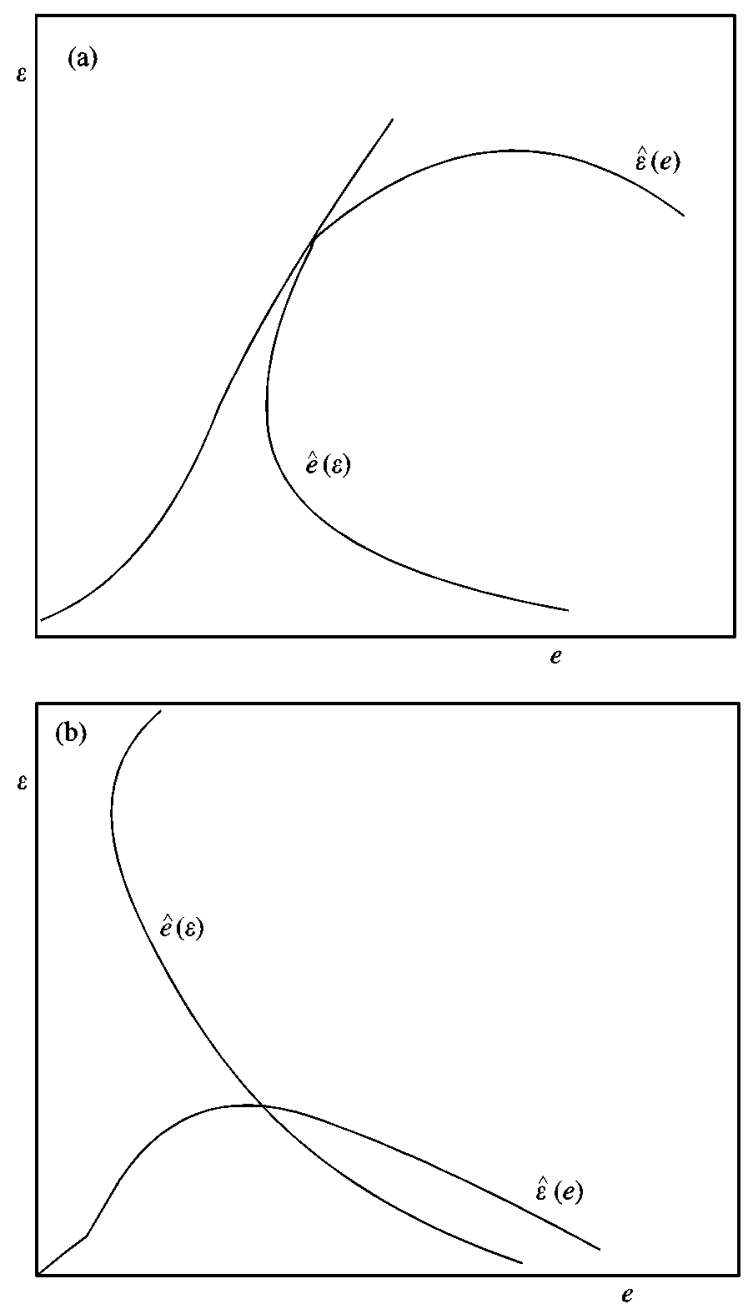

FIG. 5. The two pairs of curves $\hat{\varepsilon}(\mathrm{e})$ and $\hat{e}(\varepsilon)$ of conditional optimal values of one of the energetic variables as a function of the other, for the two non linear $C(B)$ functions shown in Fig. 3. (a) A mainly concave $C(B)$ function is assumed, that is, one with a long branch with positive $\left(\partial^{2} C / \partial B^{2}\right)$. In this case, the curve $\hat{\varepsilon}(e)$ grows for a long time before reaching its maximum at $e=\hat{e}$, whereas $\hat{e}(\varepsilon)$ has the form determined by $\partial^{2} C / \partial B^{2}$ alone. The two curves cross when their derivatives are positive. (b) A mainly convex $C(B)$ function is assumed. In this case, the branch with negative $\partial^{2} C / \partial B^{2}$ prevails, the curve $\hat{\varepsilon}(e)$ reaches its maximum soon, and the two curves cross when their derivatives are negative. The optimizations of $e$ and $\varepsilon$ are necessarily linked.

where

$$
\Delta_{1}=\frac{\partial^{2} \lambda}{\partial \varepsilon^{2}}+\frac{\partial^{2} \lambda}{\partial \varepsilon \partial e}\left(\frac{\mathrm{d} \hat{e}}{\mathrm{~d} \varepsilon}\right)_{q_{i}}
$$

and

$$
\Delta_{2}=\frac{\partial^{2} \lambda}{\partial e^{2}}+\frac{\partial^{2} \lambda}{\partial \varepsilon \partial e}\left(\frac{\mathrm{d} \hat{\varepsilon}}{\mathrm{d} e}\right)_{q_{i}} .
$$


The sign of eqns (19a) and (19b) is determined by the sign of the numerator, given that $\Delta_{1}<0$ and $\Delta_{2}<0$ according to the second-order conditions for a maximum of $\lambda$. The detailed derivation of these equations is given in the appendix.

In general, the change of the optimal value of any variable caused by the increase of a parameter can be partitioned into two components: one produced by the direct effect of the factor on the variable itself [given by the first term in the numerator of eqns (19a) and (19b)] and another produced indirectly by modifying the other variable [expressed by the term between braces in the numerator of eqns (19a) and (19b)]. Notice that both indirect effects are mediated by the mixed partial derivative $\partial^{2} \lambda / \partial \varepsilon \partial e$. This, as discussed above, can be positive or negative. The effects of particular factors are analysed henceforward.

Notice also that eqns. (A.5a) and (A.7a) (see the appendix) give, if evaluated at any $\varepsilon$ (or $e$ ), the effects of modifying $q_{i}$ on the entire curves $\hat{\varepsilon}(e)$ or $\hat{e}(\varepsilon)$. For example, $\mathrm{d} \hat{\varepsilon}(e) / \mathrm{d} q_{i}>0$ means that the effect of $q_{i}$ is to increase $\hat{\varepsilon}$ for any, i.e. to push the new $\hat{\varepsilon}(e)$ curve to lie above the unperturbed one. Thus, we could easily give graphical interpretations of the perturbation effects.

\section{INCREASES OF ANY UNAVOIDABLE MORTALITY OR OF THE AVOIDABLE MORTALITY FACTORS AFFECTING THE ADULT}

If the perturbation occurs either in any of the unavoidable mortalities $\left(q_{i}: \mu_{o}, \mu_{a}\right)$ or in the avoidable hazards affecting the adult phase $\left(q_{i}=m_{a}\right)$, we have at equilibrium that $\partial^{2} \lambda / \partial e \partial q_{i}=0$. The indirect component of $\hat{\varepsilon}$ change vanishes, and $\hat{\varepsilon}$ remains exclusively subject to the direct action of the concerned mortality factors. The optimal per offspring investment $\hat{e}$, though, is not directly affected by these factors. Its change could only be indirectly prompted through the modifications provoked by these mortality sources on total effort, when such an indirect effect exists. Analysing the modification of $\varepsilon$, note that what matters is the sign of the mixed derivative $\partial^{2} \lambda / \partial \varepsilon \partial q_{i}$. Thus, increasing unavoidable mortality favors a reduction of reproductive effort when it affects juveniles $\left(q_{i}=\mu_{o}\right)$ but an increase when it impinges on adults $\left(q_{i}=\mu_{a}\right)$, giving $\partial^{2} \lambda / \partial \varepsilon \partial \mu_{o}<0 \rightarrow \mathrm{d} \hat{\varepsilon} / \mathrm{d} \mu_{o}<0$ and $\partial^{2} \lambda / \partial \varepsilon \partial \mu_{\mathrm{a}}>0 \rightarrow \mathrm{d} \hat{\varepsilon} / \mathrm{d} \mu_{\mathrm{a}}>0$. These are compensatory strategies (León, 1983), i.e. reallocations of total energy that reduce investment on the afflicted fitness component-adult survival or effective fecundity - thereby enhancing the other component.

Intensifying the avoidable perils which jeopardize the adult stage $\left(q_{i}=m_{a}\right)$ favors an increased investment in defense at the expense of reproductive activities. This represents a direct strategy (reallocation by investing more on the affected phase; León, 1983,1988):

$$
\frac{\partial^{2} \lambda}{\partial \varepsilon \partial m_{a}}<0 \rightarrow \frac{\mathrm{d} \hat{\varepsilon}}{\mathrm{d} m_{a}}<0 .
$$

If the indirect effects of these mortality factors $\left(\mu_{o}, \mu_{a}, m_{a}\right)$ on total effort do not exist, the optimal energetic propagule size is not altered in these three situations. Optimal clutch size changes directly and exclusively with $\varepsilon$, without offspring quality modification. If the requisite cost function is purely or mainly downward concave [Fig. 3(a)] then $\partial^{2} \lambda / \partial \varepsilon \partial e<0$, and so optimal offspring size $\hat{e}$ changes in the opposite sense to $\hat{\varepsilon}$. The change of $B$ caused by $\varepsilon$ is thus reinforced by the change of $\hat{e}$. Solely or mainly convex cost [Fig. 3(b)] conduces to coincident changes of both energetic variables and therefore to opposite, mutually damping, effects on $B$.

\section{INCREASES IN AVOIDABLE MORTALITY FACTORS AFFECTING THE OFFSPRING}

Increases in the avoidable hazards that haunt the offspring $\left(q_{i}=m_{o}\right)$ affect directly both efforts. Indirect effects on $\varepsilon$ due to changes on $e$ are now possible. In the simple case of null or linear requisite cost function $C(B)$, eqns (19a) and (19b) for $q_{i}=m_{o}$ reduce to give $\partial^{2} \lambda / \partial \varepsilon \partial m_{o}>0$ and so $\mathrm{d} \hat{\varepsilon} / \mathrm{d} m_{o}$ is negative, and $\partial^{2} \lambda / \partial e \partial m_{o}<0$ and so $\mathrm{d} \hat{e} / \mathrm{d} m_{o}$ is positive, respectively. Increases in $m_{o}$ would militate towards reducing the investment on reproduction but enhance the investment on each offspring: lower number of offspring but higher quality of each one. A solely or mainly concave $C(B)$ curve [Fig. 3(a)] would reinforce these results because in this case the direct and indirect components of change have similar signs. With a mainly convex $C(B)$ curve [Fig. 3(b)] both 
components would counteract each other and this would mitigate the change in fecundity.

\section{INCREASES IN PER ADULT TOTAL ENERGY}

For the simple case $B=E \varepsilon / e$, the mixed derivatives $\partial^{2} \lambda / \partial \varepsilon \partial e$ and $\partial^{2} \lambda / \partial E \partial e$ are equal to zero at the optimum. Therefore, expression (19b) with $q_{i}=E$ vanishes at the optimum: optimal per offspring effort does not change. The change of $\hat{\varepsilon}$ is governed by the sign of the mixed derivative in the numerator:

$$
\begin{aligned}
\frac{\partial^{2} \lambda}{\partial E \partial \varepsilon}= & \frac{s\left(e ; m_{o}\right)}{e} \phi\left(\mu_{o}\right) \\
& +\frac{\partial^{2} p\left(\varepsilon ; m_{a}, E\right)}{\partial E \partial \varepsilon} \pi\left(\mu_{a}\right) .
\end{aligned}
$$

The first term is positive while the second term is assumed to be negative: the enhancement of $p(\varepsilon)$ with the increase of $\sigma$ (decrease of $\varepsilon$ ) is more pronounced at high values of available energy. This effect increases with the relative importance of the avoidable mortality sources. The entire expression (20) is positive if the first term is greater than the second one. Thus, increases in reproductive effort when adult resources augment are expected when there is a benign offspring environment with low, unavoidable as well as avoidable mortality ( $\phi$ and $s$ high) and an adverse adult environment with high mortality predominantly unavoidable ( $\pi$ low, $\partial^{2} p / \partial E \partial \varepsilon$ low). Note that the enrichment of the adult's environment would have a two-fold effect on $B$ because it enhances the scale of potential values of $B$ for any given $\varepsilon$, and favors directly the increase in optimal effort $\hat{\varepsilon}$. Opposite situations lead to a reduction of total effort with increased resources.

For fecundity functions with interactive effects between $\varepsilon$ and $e$, which appear with our nonlinear $C(B)$ function, the mixed derivatives $\partial^{2} \lambda / \partial \varepsilon \partial e$ and $\partial^{2} \lambda / \partial E \partial e$ are not zero. Assuming that they exhibit the same sign (a germane assumption due to the similar positive effects of $E$ and $\varepsilon$ on $B$ ) the following results hold:

(a) The indirect effect on $\hat{\varepsilon}$, now possible, is positive whatever the sign of its interaction with per-offspring effort $e$. (b) Whenever enhancing $E$ favors directly the increase of total effort, this will be accompanied by a reduction or increase of $e$ if the requisite cost function is mainly concave or convex [Fig. 3(a) or (b)], respectively. In this case, the indirect changes reinforce the direct effects on $\varepsilon$ and $e$ induced by $E$.

(c) Whenever the reduction of optimal total effort is favored by enriching the adult environment, the direct and indirect effects on $\hat{e}$ oppose each other, e.g. if the $C(B)$ curve is mainly convex [Fig. 3(b)], per-offspring investment will be directly and positively affected by $E$, but indirectly and negatively affected by an $\varepsilon$ reduction.

\section{Discussion}

Life-history theory has mainly focused on producing models of how separate components of the life cycle contribute to fitness, considering limited trade-offs between these components, and performing constrained optimization analysis of such problems (Sibly \& Calow, 1986; Roff, 1992; Stearns, 1992; Charlesworth, 1994). Consequently, the experimental or field evaluations of these models have often separately measured variables involved in simple trade-offs (Roff, 1992; Stearns, 1992).

Studies considering simultaneous comparisons of several variables, on the other hand, were mainly undertaken under the patronage of theories which stressed the selective action of some environmental factors such as population density ( $r / K$ selection, MacArthur, 1972), stress (Grime, 1979), and adversity (Southwood, 1977; Greenslade, 1983). Although simplistic in their overemphasis, these encompassing theories have had the virtue of attempting to understand why several adaptive traits tend to occur together in certain circumstances.

Theories that contain the proper parameters, on the other hand, see the life history as a patchwork of disconnected aspects. They hardly can, therefore, explain the kind of plural comparisons that were initiated under the auspices of the "environmental" theories. So, we will have to include in a more encompassive framework the kind of nonlinear, synergistic effects that we have put out here. To insist on this, we will show now 
a few examples of how the disconnected paradigm is insufficient to understand simultaneous differences in some traits, which seem to require an integrative approach to be accounted for.

\section{MODIFYING UNAVOIDABLE MORTALITY}

The elegant study of Trinitarian guppies (Poecilia reticulata) by Reznick and his colleagues established unequivocally the selective consequences of predation on juveniles or adults. Reznick and Endler (1982) identified three kinds $(\mathrm{C}, \mathrm{R}, \mathrm{A})$ of stream in which the main predators were: (C) Crenicichla alta, predating mostly on adults, (R) Rivulus hartii, on juveniles, (A) Aequidens pulcher, with only slight predation on all size classes. The life history parameters of the guppies rank in the following order. Reproductive effort: $\mathrm{C}>\mathrm{A}>\mathrm{R}$; litter size: $\mathrm{C}>\mathrm{A}>\mathrm{R}$; offspring size: $\mathrm{R}>\mathrm{A}>\mathrm{C}$. The genetic bases were established by Reznick (1982a,b). Moreover, Reznick et al. (1990) performed a selection experiment changing predation on adults to predation on juveniles. They found the whole set of traits to move in the same direction as the observed natural differences after 11 years (30-60 generations). The comparisons have been extended to 40 new localities in Trinidad, Tobago and Venezuela, and to new types of predator communities, obtaining patterns that support the original results (Reznick et al., 1996a; Reznick et al., 1996b, Reznick \& Bryga, 1996).

Now, these results have been considered as confirmatory of the current life-history theory, but they are not so. Indeed, differences in reproductive effort accord with theory (Stearns, 1992). But the traditional Smith-Fretwell kind of model would predict no change in offspring size when additional unavoidable mortality is imposed on (or relieved from) juveniles. This would also be so, of course, in integrated models lacking our requisite cost (like Winkler \& Wallin, 1987) or having it in a mere linear fashion (Zhang, 1998). Thus, a nonlinear requisite cost is mandatory here. More specifically, a type a $C(B)$ function, with a long concave $\left(\partial^{2} C / \partial B^{2}<0\right)$ branch, would explain the observed results. This is biologically plausible in guppies, since they are viviparous and therefore the cost required for producing the first few members of the litter is probably much bigger than the additions. With such an assumption, and the almost no-predation condition (A) as reference, we predict (or explain) the observed patterns as follows. The $\mathrm{C}$ pattern (high $\hat{\varepsilon}$, high $\hat{B}$, low $\hat{e}$ ) results from increasing $\mu_{a}$, interpreted in this case as unavoidable predation on the adult. The opposite $\mathrm{R}$ pattern (low $\hat{\varepsilon}$, low $\hat{B}$, high $\hat{e}$ ) would be the selective consequence of increasing $\mu_{o}$, unavoidable predation on juveniles.

Notice that the changes in offspring size predicted by our model in these cases are not directly adaptive. There is no direct benefit in reducing $\hat{e}$ when predators impinge on adults, or in augmenting it when predators equally attack juveniles whatever their size. But the reduction helps to increase the number $B$ which compensates for higher adult mortality, and the augmentation helps to diminish the number of candidates to be victimized by enemies preferring to eat the young. We call this kind of responses indirect compensatory strategies.

AVOIDABLE OFFSPRING AND UNAVOIDABLE

ADULT MORTALITY VS. UNAVOIDABLE JUVENILE AND AVOIDABLE ADULT MORTALITY

Hart \& Begon (1982) (see also Begon, 1985) compared several life history parameters of populations of winkles (Littorina rudis) from two spatially adjacent but distinct habitats. One of the habitats (B) had loose boulders on a solid rock substratum, whereas the other $(\mathrm{C})$ had crevices and depressions in rock stacks. Individuals in the "boulders" habitat were found to make a smaller reproductive effort, delay maturity longer and produce more numerous, smaller young than individuals in the "crevice" habitat.

Our interpretation, adopted from that advanced by Hart \& Begon (1982), and further elaborated by Begon (1985), is as follows. In $\mathrm{B}$ habitat, predation and crushing by boulders affect all offspring irrespective of size, but a thick shell in adults bestows effective protection against both kinds of adversity. Thus, defense (against avoidable sources of mortality, $m_{a}$ ) requires sacrificing adult effort $\varepsilon$, whereas the juveniles face unavoidable offspring mortality, $\mu_{o}$, which push in the same direction. A requisite cost function with a long convex increasing branch $\left(\partial^{2} C / \partial B^{2}>0\right)$ would be required to prompt a decrease of offspring size $\hat{e}$. 
The $C$ habitat, on the other hand, prizes offspring size in competition for crevices, but adults have difficulties in finding slits to accommodate them, so that they suffer unavoidable mortality $\mu_{a}$ by dislodgment and predation. The latter factor favors increasing reproductive effort. The avoidable character of offspring mortality sources promotes a larger size at birth but a decrease of $\hat{\varepsilon}$. A long convex branch in the requisite cost would, though, push for a compensatory increase of $\hat{\varepsilon}$.

Unfortunately, for this case we do not have an intermediate "unperturbed" example which could serve as reference, as the light predation situation served for the guppies. We do not have, either, reasons to infer the shape of the $C(B)$ curve.

Montague et al. (1981) presented a simple mechanistic model of Drosophila egg production, based on the numbers of ovarioles and the rate of egg maturation. They thereby evaluated reproductive traits in 35 Hawaiian Drosophilidae studied by Kambysellis \& Heed (1971), and found three characteristic groups of species. Groups 1 and 2 have relatively low reproductive effort, large eggs and low clutch size. The larvae utilize stable substrate where big larvae presumably enjoy competitive advantages. The adults face avoidable desiccation problems which require energy investment, thus demanding reproductive effort reduction. A mainly concave $C(B)$ function - perhaps due to costly development of the first few ovarioles - would then promote the production of a few, large eggs. Group 3 species, on the other hand, have high reproductive effort, small eggs and high clutch. They utilize unpredictable yet productive breeding sites. So, females may have to retain eggs until suitable sites are found. These, once located, should provide food for large numbers of small larvae. Group 3 adults live in rain and cloud forest environments with less demand for desiccation resistance. Their reproductive effort can be higher, and the postulated type b $C(B)$ curve could explain small eggs.

\section{CHANGES IN AVAILABLE ENERGY}

Kawano \& Masuda (1980) studied reproductive allocation in five populations of Heloniopsis orientalis, an evergreen liliaceous perennial herb, along an altitudinal gradient from lowland or mountain forest to alpine meadows in Japan (100, 200, 900, 1.900 and $2.600 \mathrm{~m}$ above sea level). The growing season shortens progressively as the altitude increases, from 330 to 135 days. As Kawano and Masuda point out "the length of the growing season would be expected to affect the total amount of energy available to the plants" (p. 311). Thus, we have a decrease in our parameter $E$.

The plants of $H$. orientalis allocate increasingly greater energy to reproductive structures as elevation goes up but, on the contrary, show a marked decrease in "reproductive capacity" (numbers of seeds). The cost per seed ("relative amount of energy invested to producing a single propagule") increases markedly with altitude, but the exceedingly minute size of the (wind-dispersed) seeds does not seem to vary. What does increase with altitude, and apparently accounts for the cost per propagule produced, is energy allocation to ancillary reproductive organs such as perianths, capsules, bracts, and scapes.

We seem to have here a case in which increasing $E$ (decreasing the altitude to have a longer growing season) elicits a reduction of total reproductive effort $\hat{\varepsilon}$. Seedlings of this species probably suffer high unavoidable mortality since the habitat (closed, subclimax or climax communities) imposes very limited effective recruitment. This is one of the conditions in which our eqn (20) favors a reduction of $\hat{\varepsilon}$ when $E$ increases. Moreover, the evaluation of costs per seed suggests a predominantly concave $C(B)$ function, which in turn gives a negative interaction between $\varepsilon$ and $e$. Thus, we would expect compensation of direct and indirect effects on $\hat{e}$, and so little selective chances in it, as seems to be the case. Also, this species is windpollinated, and this could make $C(B)$ merely linear, as suggested by Sakai (1996) to explain the independence of seed size with respect to plant size (an index of E) in Rumex acetosella, studied by Escarré \& Thompson (1991). Such linearity of $C(B)$ would make $\hat{e}$ independent of changes of $E$ brought about by modifying the altitude in the Heloniopsis case discussed here.

Sakai \& Sakai (1995) constructed a model of seed size determination in which the energy $T$ available to each flower is partially used 
(in amount $A$ ) to build up pollen capture dispositives [which would determine the number of outcrossed seeds $V(A)]$ and the rest used to provision the seeds. Sakai (1995) extended this to include the numbers of flowers in the picture, and so, total plant pollen attractiveness and total seed production. Their model is much akin to ours in such a division of reproductive energy, although they used an investment paradigm, whereas we appeal to cost production theory. They did not consider, nevertheless, the problem of reproductive vs survival effort allocation.

Sakai \& Sakai (1995) and Sakai $(1995,1996)$ were interested in seed size variation with the plant resource status (our $E$ ), not predicted by the classic Smith \& Fretwell (1974) kind of model, but observed once and again (references in Sakai \& Sakai, 1995). Several hypotheses have been conceived to explain this (see Sakai \& Sakai, 1995, Table I). Sakai \& Sakai (1995) proposed, and Sakai (1995) modified, what they call the "fertilization efficiency hypothesis". Suppose the pollen captured by a plant increases with diminishing returns as a function of allocation to attractive structures. Then, as these structures become larger they catch less extra pollen per additional enlargement, and so it is more advantageous to increase seed size instead of numbers. Sakai \& Sakai $(1995,1997)$ obtained results consistent with the hypothesis in Lilium auratum, Impatiens noli-tangere and Viola grypoceras. Furthermore, Sakai (1996) found that nine reported cases in which larger plants produce larger seeds correspond to self-incompatible and/or highly outcrossing, animal pollinated species.

The "pollination efficiency hypothesis" clearly produces the same results ( $\hat{e}$ grows with $E$ ) in our model - with $C(B)$ convex or mainly so (type II curve) - whenever increasing $E$ favors enhancing the reproductive effort $\hat{\varepsilon}$. But there are other possibilities produced by the hypothesis and revealed by our joint allocation model. For instance, when an increase of $E$ bids for a reduction of $\hat{\varepsilon}$ [see the analysis of our eqn (20)], Sakai's hypothesis could predict a very slight or null change of seed size $(\hat{e})$ accompanying plant size increase. This could be the case of the Gentianaceae Sabatia angularis, studied by Dudash $(1991,1993)$ and showing such independence of $\hat{e}$ and $E$ changes, despite being highly outcrossed and pollen-limited. Another interesting possibility is that pollen limitation $(C(B)$ type II) could provoke changes in optimal seed size not induced by an increase of $E$, but by the action of another factor (unavoidable adult mortality, for instance) that would militate for augmenting $\hat{\varepsilon}$. Such an indirect effect would link Sakai's hypothesis to other sub-sections of this discussion.

\section{REFERENCES}

BABCOCK, R., Mundy, C., KeEsing, J. \& Oliver, J. (1992). Predictable an impredictable spawning events: in situ behavioural data from free-spawninig coral reef invertebrates. Invert. Reprod. Dev. 22, 213-228.

BEGON, M. (1985). A general theory of life-history variation. In: Behavioral Ecology (Sibly, R. M. \& Smith, R. H., eds), pp. 91-97. Oxford: Blackwell.

BELL, G. (1980). The costs of reproduction and their consequences. Am. Nat. 116, 45-76.

Brockelman, W. Y. (1975). Competition, the fitness of offspring and optimal clutch size. Am. Nat. 109, 677-699.

Brown, J. S. \& Venable, D. L. (1986). Evolutionary ecology of seed-bank annuals in temporally varying environments. Am. Nat. 127, 31-47.

BUCKLAND-NICKS, J. (1993). Hull cupules of chiton eggs: parachute structures and sperm focusing devices? Biol. Bull. 186, 269-276.

Calow, P. (1979). The cost of reproduction - a physiological approach. Biol. Rev. 54, 23-40.

Caswell, H. \& Real, L. A. (1987). An approach to the perturbation analysis of optimal life histories. Ecology 68, 1045-1050.

Charlesworth, B. (1990). Optimization models, quantitative genetics and mutation. Evolution 44, 520-538.

Charlesworth, B. (1994). Selection in Age-Structured Population, 2nd Edn. Cambridge: Cambridge University Press.

Charlesworth, B. \& León, J. A. (1976). The relation of effort reproductive to age. Am. Nat. 110, 449-459.

Charnov, E. (1982). The Theory of Sex Allocation. Princeton: Princeton University Press.

Charnov, E. L. \& Schaffer, W. M. (1973). Life history consequences of natural selection: Cole's result revisited. Am. Nat. 107, 781-793.

Chiang, A. C. (1974). Fundamental Methods of Mathematical Economics. New York: McGraw-Hill.

DudAsh, M. R. (1991). Plant size effects and female and male function in hermaphrodite Sabatia angularis (Gentianaceae). Ecology 72, 1004-1012.

DUDASH, M. R. (1993). Variation in pollen limitation among individuals of Sabatia angularis (Gentianaceae). Ecology 74, 959-962.

EscARré, J. \& ThOMPSON, J. D. (1991). The effect of successional habitat variation and time of flowering on seed production in Rumex acetosella. J. Ecol. 79, 1099-1112.

GAdGil, M. \& Bossert, W. H. (1970). Life history consequences of natural selection. Am. Nat. 102, 52-64. 
Geritz, S. A. H. (1995). Evolutionarity stable seed polymorphism and small-scale spatial variation in seedling density. Am. Nat. 146, 685-707.

GOODMAN, D. (1979). Regulating reproductive effort in a changing environment. Am. Nat. 113, 735-743.

Greenslade, P. J. M. (1983). Adversity selection and the habitat templet. Am. Nat. 122, 352-365.

Grime, J. P. (1979). Plant Strategies and Vegetation Processes. Chichester: Wiley.

HART, A. \& BEGON, M. (1982). The status of general reproductive-strategy theories, illustrated in winkles. Oecologia (Berl) 52, 37-42.

Harvey, P. H. \& Bradbury, J. W. (1991). Sexual Selection. In: Behavioural Ecology. An Evolutionary Approach (Krebs, J. R. and Davies, N. B., eds), pp. 203-233. Oxford: Blackwell Scientific Publishers.

HEndERSOn, J. M. \& QUANDT, R. E. (1971). Microeconomic Theory: a Mathematical Approach, 2nd Edn. New York: McGraw-Hill.

HERNÁNDEZ, M. J. \& LEÓN, J. A. (1995). Evolutionary perturbations of optimal life histories. Evol. Ecol. 9, 478-494.

Hernández, M. J. \& LEÓn, J. A. (2000). Adaptatives strategies in size structured populations: optimal patterns and perturbation analysis. Evol. Ecol. Res. 2, 565-582.

Kambysellis, M. P. \& HeED, W. B. (1971). Studies of oogenesis in natural populations of Drosophilidae I. Relation of ovarian development and ecological habitats of the Hawaiian species. Am. Nat. 105, 31-49.

Kawano, S. \& Masuda, J. (1980). The productive and reproductive biology of flowering plants. VII. Resource allocation and reproductive capacity in wild populations of Heloniopsis orientalis. Oecologia (Berl) 45, 307-317.

KisDi, É. \& MeszÉNA, G. (1993). Density dependent life history evolution in fluctuating environments. In: Adaptation in Stochastic Environments (Yoshimura, J. \& Clark, C. W. eds), Lecture Notes in Biomathematics, Vol. 98, pp. 26-62. Berlin: Springer-Verlag.

KIsDi, É., MeszénA, G. \& PÁstor, L. (1998). Individual optimization: mechanisms shaping the optimal reaction norm. Evol. Ecol. 12, 211-221.

LAW, R. (1979). Ecological determinants in the evolution of life histories. In: Population Dynamic. Twentieth Symposium of British Ecological Society (Anderson, R. M. \& Turner, D. B., eds), pp. 81-103. Oxford: Blackwell Scientific Publishers.

LEÓN, J. A. (1976). Life histories as adaptive strategies. J. theor. Biol. 107, 169-172.

LEÓN, J. A. (1983). Compensatory strategies of energy investment in uncertain environments. In: Population Biology (Freedman, H. I., ed.), Lectures Notes in Biomathematics, Vol. 52. 1985-90. Berlin: Springer-Verlag.

LEÓN, J. A. (1984). El dilema uniparidad vs multiparidad. Acta Científica Venezolana 35, 109.

LEÓN, J. A. (1988). Avoidable mortality in life history theory. In: Mathematical Ecology (Hallan, T., Gross, G. \& Levin, S., eds). Singapore: World Scientific.

LEÓN, J. A. Comparative statics of life history evolution. Theor. Popul. Biol. (in press).

LLOYD, D. G. (1987). Selection of offspring size at independence and other size-versus-number strategies. Am. Nat. 129, 800-817.

Low, B. S. (1978). Environmental uncertainty and the parental strategies of marsupials and placentals. Am. Nat. 102, 197-213.
MacArthur, R. H. (1972). Geographical Ecology. New York: Harper \& Row.

Maynard Smith, J. (1978). Optimization theory in evolution. Ann. Rev. Ecol. Syst. 9, 31-56.

MaYnard SMith, J. (1982). Evolution and the Theory of Games. Cambridge: Cambridge University Press.

MichOD, R. E. (1979). Evolution of life histories in response to age-specific mortality factors. Am. Nat. 113, 531-550.

MeszénA, G. \& PAszToR, E. (1990). Population regulation and optimal life history strategies. In: Organizational Constraints on the Dynamics of Evolution (Maynard Smith, J. \& Vida, G., eds.), pp. 321-332. Manchester: Manchester University Press.

Miller, R. L. (1985). Demostration of sperm chemotaxis in Echinodermata: Asteroidea, Holothuroidea and Ophiuroidea. J. Exp. Zool. 234, 283-414.

MoLE, S. (1994). Trade-offs and constraints in plant-herbivore defense theory: a life-history perspective. Oikos 71, 3-12.

Montague, J. R., Mangan, R. L. \& Starmer, W. T. (1981). Reproductive allocation in the Hawaiian Drosophilidae: egg size and number. Am. Nat. 118, 865-871.

MORRIS, D. W. (1996). State-dependent life histories, Mounford's hypothesis, and the evolution of brood size. J. Anim. Ecol. 65, 43-51.

Nossbaun, R. A. \& Schultz, D. L. (1989). Coevolution of parental care and egg size. Am. Nat. 133, 591-603.

PARKER, G. A. \& BEGON, M. (1986). Optimal egg size and clutch size: effects of environment and maternal phenotype. Am. Nat. 128, 573-592.

PARKer, G. \& MAYNARD SMith, J. (1990). Optimality theory in evolutionary biology. Nature 348, 27-33.

PARTRIDGE, L. (1989). An experimentalists approach to the role of cost of reproduction in the evolution of life histories. In: Toward a more Exact Ecology (Grubb, D. J. \& Whittaker, J. B. eds), pp. 231-246. London: Blackwell Scientific Publishers.

PÁSZTOR, E. (1988). Unexploited dimensions of optimization life history. In: Population Genetics and Evolution (de Song, G., ed.), pp. 19-33. Berlin: Springer-Verlag.

Podolski, R. D. \& Strathman, R. R. (1996). Evolution of egg size in free spawners: consequences of the fertilizationfecundity trade-off. Am. Nat. 148, 160-173.

REEKIE, E. G. \& BAZZAZ, F. A. (1987). Reproductive effort in plants. I. Carbon allocation to reproduction. Am. Nat. 129, 876-896.

REZNICK, D. (1982a). Genetic determination of offspring size in the guppy (Poecilia reticulata). Am. Nat. 120, 181-188.

REZNICK, D. (1982b). The impact of predation on life history evolution in Trinidadian guppies: the genetic components of observed life history differences. Evolution 36, 1236-1250.

REZNICK, D. (1985). Costs of reproduction: an evaluation of the empirical evidence. Oikos 44, 257-267.

REZNICK, D. (1992). Measuring costs of reproduction. Trends. Ecol. Evol. 7, 42-45.

REZNICK, D. \& BRYGA, H. (1996). Life history evolution in guppies. 5. Genetics basis of parallelism in life histories. Am. Nat. 147, 339-359.

Reznick, D., Bryga, H. \& Endler, J. A. (1990). Experimentally induced life-history evolution in a natural population. Nature 346, 357-359.

ReZnick, D., Butler IV, M. V. \& Rodd, H. (1996b). Differential mortality as a mechanisms for natural selection in the guppy (Poecilia reticulata). Evolution 50, 1651-1660. 
REZNICK, D. \& ENDler, J. A. (1982). The impact of predation on life history evolution in Trinidadian guppies (Poecilia reticulata). Evolution 36, 160-177.

REZnICK, D., RodD, F. H. \& CÁRdENAS, M. (1996a). Life history evolution in guppies. 4. Parallelism in life history phenotypes. Am. Nat. 147, 319-338.

RofF, D. A. (1992). The Evolution of Life Histories: Theory and Analysis. London: Chapman \& Hall.

RoFF, D. A. (1994). Optimality modelling and quantitative genetics: a comparison of two approaches. In: Quantitative Genetics Studies of Behavioral Evolution (Boake, C. R. B., ed.), pp. 49-66. Chicago: University of Chicago Press.

RyAN, M. J. (1997). Sexual selection and mate choice. In: Behavioural Ecology. An Evolutionary Approach (Krebs, J. R. \& Davies, N. B., eds), pp. 179-202. Oxford: Blackwell Scientific Publishers.

SAKAI, S. (1995). A model for seed size variation among plants. Evol. Ecol. 9, 495-507.

SAKAI, S. (1996). Using phylogenies to explain seed size variation among plants. J. Evol. Biol. 9, 243-252.

SAKAI, S. \& SAKAI, A. (1995). Flower size-dependent variation in seed size: theory and a test. Am. Nat. 145, 918-934.

SARgeAnt, R. C., TAYlOR, P. D. \& Gross, M. R. (1987).

Parental care and the evolution of egg-size in fishes. Am. Nat. 129, 32-46.

SCHAFFER, W. M. (1974). Selection for optimal life histories: the effects of age structure. Ecology 55, 291-301.

SCHAFFER, W. M. \& GADGIL, M. D. (1975). Selection for optimal life histories in plants. In: The Ecology and Evolution of Communities (Cody, M. \& Diamond, J., eds). Cambridge, MA: Belknap Press.

Schaffer, W. M. \& RosenzWeiG, M. L. (1977). Selection for optimal life histories. II. Multiple equilibrium and the evolution of alternative reproductive strategies. Ecology $\mathbf{5 8}, 60-72$.

Seger, J. \& Stubblefeld, J. W. (1996). Optimization and adaptation. In: Adaptation (Rose, M. R. \& Lauder,G. V., eds), pp. 93-124. San Diego: Academic Press.

Sibly, R. \& Calow, P. (1982). Asexual reproduction in Protozoa and invertebrates. J. theor. Biol. 96, 401-424.

Sibly, R. \& CAlOw, P. (1986). Physiological Ecology of Animals. An Evolutionary Approach. Oxford: Blackwell Scientific Publishers.

SIKES, R. S. (1998). Unit pricing: economics and the evolution of litter size. Evol. Ecol. 12, 179-190.

Silberberg, E. (1978). The Structure of Economics. A Mathematical Analysis. New York: McGraw-Hill.

Smith, C. C. \& Fretwell, S. D. (1974). The optimal balance between size and number of offspring. Am. Nat. 108, 499-506.

Sinervo, B. \& DE NARdo, D. F. (1996). Costs of reproduction in the wild: path analysis of natural selection and experimental tests of causation. Evolution 50, 1299-1313.

Southwood, T. R. E. (1977). Habitat, the templet for ecological strategies. J. Anim. Ecol. 46, 337-365.

STEARNS, S. (1992). The Evolution of Life Histories. Oxford: Oxford University Press.

Taylor, H. M., Gourley, R. S., Lawrence, C. E. \& Kaplan, R. S. (1974). Natural selection of life history attributes: an analytical approach. Theor. Popul. Biol. 5, 104-122.

VANCE, R. R. (1973a). On reproductive strategies in marine bottom invertebrates. Am. Nat. 107, 339-352.
VANCE, R. R. (1973b). More on reproductive strategies in marine bottom invertebrates. Am. Nat. 107, 352-361.

Venable, D. L. (1988). Size-numbers trade-offs and the variation of seed size with plant resource status. Am. Nat. 140, 287-304.

Winkler, D. W. \& Wallin, K. (1987). Offspring size and number: a life history model linking effort per offspring and total effort. Am. Nat. 129, 708-720.

ZHANG, D. Y. (1998). Evolutionarily stable reproductive strategies in sexual: IV. Parent-offspring conflict and selection of seed size in perennial plants. J. theor. Biol. 192, 143-153.

ZhANG, D. Y. \& JiANG, X.-H. (1997). Evolutionary stable reproductive strategies in sexual organisms: III. The effects of lottery density dependence and pollen limitation. J. theor. Biol. 185, 223-231.

ZHANG, D. Y. \& JiANG, X.-H. (1998). Evolutionarily stable reproductive strategies in sexual organisms. Part V: joint effects of parent-offspring conflict and sibling conflict in perennial plants. J. theor. Biol. 192, 275-281.

ZhanG, D. Y., Jiang, X.-H \& ZhaO, S. L. (1996). Evolutionarily stable reproductive strategies in sexual organisms: II. Dioecy and optimal resource allocation. Am. Nat. 147, 1115-1123.

ZHANG, D. Y. \& WANG, G. (1994). Evolutionarily stable reproductive strategies in sexual organisms: an integrated approach to life-history evolution and sex allocation. Am. Nat. 144, 65-75.

\section{APPENDIX}

The effect of an infinitesimal change of parameter $q_{i}$ on $\hat{\varepsilon}$ and $\hat{e}$ is given by

$$
\begin{gathered}
\frac{\partial \hat{\varepsilon}}{\partial q_{i}}=-\frac{1}{D}\left(\frac{\partial^{2} \lambda}{\partial e^{2}} \frac{\partial^{2} \lambda}{\partial \varepsilon \partial q_{i}}-\frac{\partial^{2} \lambda}{\partial \varepsilon \partial e} \frac{\partial^{2} \lambda}{\partial e \partial q_{i}}\right), \\
\frac{\partial \hat{e}}{\partial q_{i}}=-\frac{1}{D}\left(\frac{\partial^{2} \lambda}{\partial \varepsilon^{2}} \frac{\partial^{2} \lambda}{\partial e \partial q_{i}}-\frac{\partial^{2} \lambda}{\partial \varepsilon \partial e} \frac{\partial^{2} \lambda}{\partial \varepsilon \partial q_{i}}\right), \\
\text { where } \quad D=\frac{\partial^{2} \lambda}{\partial \varepsilon^{2}} \frac{\partial^{2} \lambda}{\partial e^{2}}-\left(\frac{\partial^{2} \lambda}{\partial \varepsilon \partial e}\right)^{2} .
\end{gathered}
$$

Multiplying $D$ and the expression between braces in eqn (A.1) by $\left(\partial^{2} \lambda / \partial e^{2}\right)^{-1}$,

$$
\frac{\mathrm{d} \hat{\varepsilon}}{\mathrm{d} q_{i}}=-\frac{\partial^{2} \lambda / \partial \varepsilon \partial q_{i}+\partial^{2} \lambda / \partial \varepsilon \partial e\left(\mathrm{~d} \hat{e} / \mathrm{d} q_{i}\right)_{\hat{\varepsilon}}}{\partial^{2} \lambda / \partial \varepsilon^{2}+\partial^{2} \lambda / \partial \varepsilon \partial e(\mathrm{~d} \hat{e} / \mathrm{d} \varepsilon)_{q_{i}}}
$$

where

$$
\left(\frac{\mathrm{d} \hat{e}}{\mathrm{~d} q_{i}}\right)_{\hat{\varepsilon}}=-\frac{\partial^{2} \lambda / \partial e \partial q_{i}}{\partial^{2} \lambda / \partial e^{2}}
$$


and

$$
\left(\frac{\mathrm{d} \hat{e}}{\mathrm{~d} \varepsilon}\right)_{q_{i}}=-\frac{\partial^{2} \lambda / \partial \varepsilon \partial e}{\partial^{2} \lambda / \partial e^{2}} .
$$

Expressions (A.5a) and (A.5b) are obtained by implicit differentiation of $\partial \lambda\left(\varepsilon, \hat{e} ; q_{i}\right) / \partial e=0$.

Multiplying $D$ and the expression between braces in eqn (A.2) by $\left(\partial^{2} \lambda / \partial \varepsilon^{2}\right)^{-1}$,

$$
\frac{\mathrm{d} \hat{e}}{\mathrm{~d} q_{i}}=-\frac{\partial^{2} \lambda / \partial e \partial q_{i}+\partial^{2} \lambda / \partial \varepsilon \partial e\left(\mathrm{~d} \hat{\varepsilon} / \mathrm{d} q_{i}\right)_{\hat{e}}}{\partial^{2} \lambda / \partial e^{2}+\partial^{2} \lambda / \partial \varepsilon \partial e(\mathrm{~d} \hat{\varepsilon} / \mathrm{d} e)_{q_{i}}}
$$

where

$$
\left(\frac{\mathrm{d} \hat{\varepsilon}}{\mathrm{d} q_{i}}\right)=-\frac{\left(\partial^{2} \lambda / \partial q_{i} \partial \varepsilon\right)}{\left(\partial^{2} \lambda / \partial \varepsilon^{2}\right)}
$$

and

$$
\left(\frac{\mathrm{d} \hat{\varepsilon}}{\mathrm{d} e}\right)_{q_{i}}=-\frac{\left(\partial^{2} \lambda / \partial \varepsilon \partial e\right)}{\left(\partial^{2} \lambda / \partial \varepsilon^{2}\right)}
$$

expressions obtained by implicit differentiation of: $\partial \lambda / \partial \varepsilon\left(\hat{\varepsilon}, e ; q_{i}\right)=0$. 